general effects, so much so that these vulnerant fish might well be called the suakes of the sea. The poison is clear, transparent, and very slightly acid, and not at all viscid. to is only forced into the canals of the spine at the moment of use; at other times it lies in the gland. In any case it is only secreted in the smallest quantity, but this secretion goes on more rapidly in the summer when the spawning season is on hand. This animal-chemical alkaloidal poison introduced locally produces within a few hours necrotic changes and a dead area follows. This is caused by its special action on the trophic nerves. Indeed, its special action seems to be on nerve tissue, as witness the generai effects apart from local changes-pains, intense stabbing sensations, tremors, convulsions, delirium. Then the heart is much inhibited, and this gives rise to feelings of suffocation and impending death.

This alkaloid has not yet been isolated, and if it should be done will be found to be more or less of the same group as the snake alkaloids.

Galashiels, N.B.

\section{CASE OF ILOCALISED DYSTROPHIC (?) RHEUMATOID ARTHRITIS.}

By A. H. CARTER, M.D., F.R C P. Lond.,

SENIOR PHYSICLAN TO RUEKX'S HOSPITAL, IJIRMINGHAM; AND PROFESSOR OF THERAPEDTICS, MASON COLLEGE.

A MAX aged thirty-five years was admitted into Queen's Hospital, Birmingham, on Jan. 1st, 1896. He was a worker in brass, and was in the habit of working with his arms on a shelf nearly as high as his shoulders-a forced position, which frequently caused cramp in his arms. Also for some reason in the course of his work he frequently put the metal into his mouth to moisten it, and in consequence had a constant metallic taste. His family history is good, with the exception that his mother (aged sixty-five years) is slightly cheumatic. He had always enjoyed good health until his present illness. Nine years ago he had severe rheumatic pains in his right elbow, the whole arm becoming weak and painful on movement. His right shoulder gradually became stiff until in the course of three or four years the limb could not be moved from his side. Meanwhile, the muscles about the right shoulder wasted. He had occasional pains in other joints, but only temporarily, without causing further trouble. $\mathrm{He}$ then went to a bone-setter, who forcibly wrenched the joint about and secured much more mobility. His after-treatment, consisted of daily local massage and manipulation, under which he rapidly regained, not only more movement, but the muscles around the joint much increased in size. A month later an abscess formed under the joint and burst into the armpit. This continued to cischarge for a year, healed for three months, then discharged for another nine months, when it finally healed. During the latter year the shoulder again became stiff, with "uenewed rapid wasting of the muscles, and the arm at this joint had been helpless ever since. On admission the right shoulder exhibited the appearance shown in the accompany. ing illustrations, taken from photographs. The deltoid, supra-, and infra-spinatus muscles were atrophied beyond recognition, and gave no response to electrical stimulation, whether constant or interrupted. The biceps and pectoral muscles were slightly atrophied (probably from disuse), but gave normal electrical reactions. The right shoulder-joint was ankylosed, but on firmly grasping the scapula very slight movement was obtainable, suggesting a fibrous union. No deformity or marked bony outgrowth could be detected. The nutrition of the right forearm was normal, and its circumference was half an inch greater than that of the left, while the movements and power of the right forearm and hand were perfect. Nothing abnormal about any other joint or muscle was observed. The right knee-jerk was obviously exaggerated. The teeth exhibited a greenish stain close to the edge of the gums, the tongue was broad and labby, and indented by the teeth. The appetite was bad, catulence occurred after meals, and the bowels were costive. The urine was normal.

Remarks. - I regard the above case as a typical instance of localised rheumatoid arthritis. Beyond a rather doubtful allusion to vague pains in some of the other joints for a short period during his illness there was no nistory of the systemic and visceral di-turbances which so commonly characterise chronic rleumatism and gout. The absence also of any symmetrical implication of the left shoulder strengthens the view that the artbritis is the result of Jocal, rather than of general, disturbance. It is dittisult to say whether the degenerative changes in the cartilages and bones (so characteristic of true rueumatoir arthritis) are present or not,

IIG. 1.

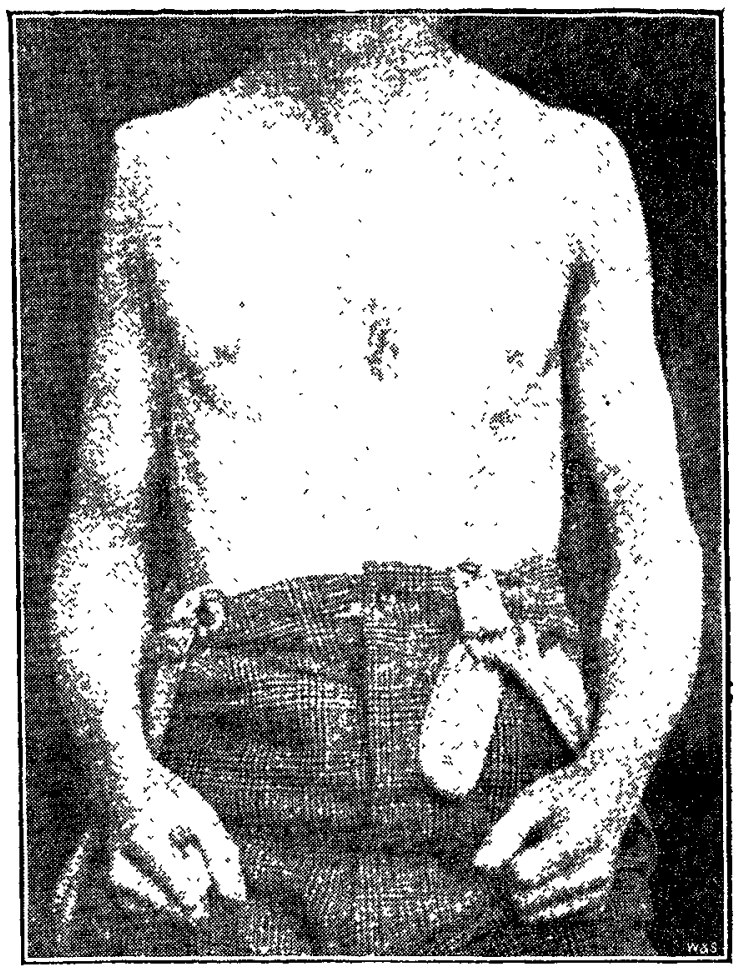

owing to the fact that the patient did not come under observation until ankylosis had been already established. Monarticular rheumatoid arthritis often dates, as is well known, from a local injury either to the joint itself or to the neighbouring structures. In the present instance no history could be obtained of any injury to account for the first onset of the joint trouble; but the very rapid

FIG. 2.

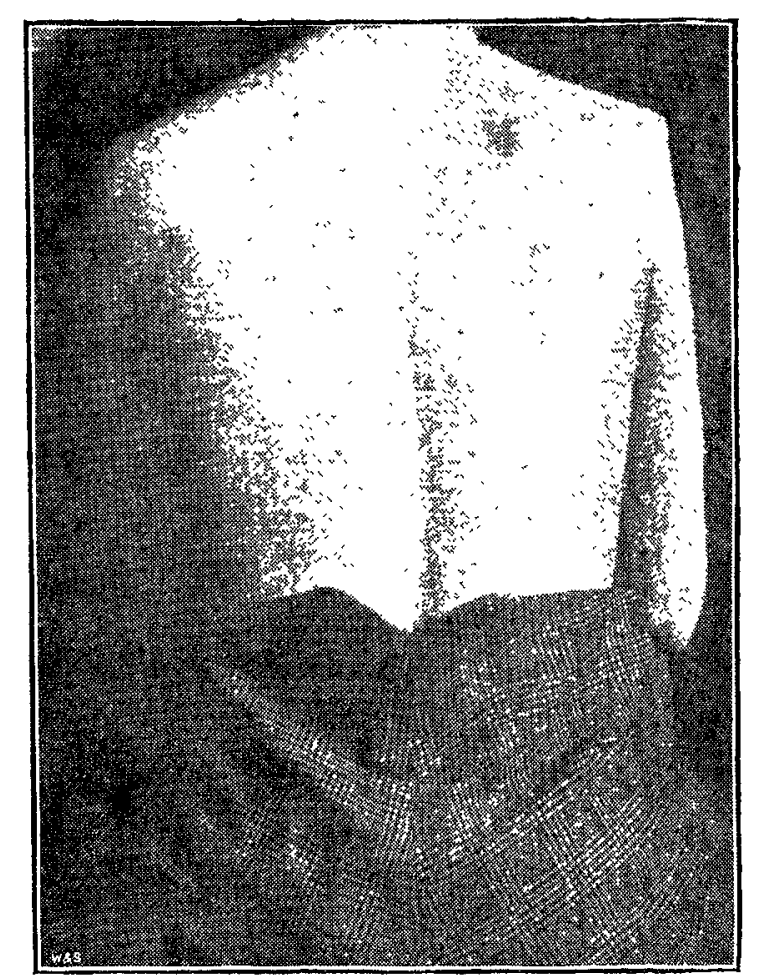

relapse of ankylosis and muscular atrophy which followed the bone-setter's violent manipulations leave little room for donbling the unfavourable influence of the local injuries then inflicted upon the joint structures. It is a noteworthy fact in this counexion that the supra- 
scapular nerve (supplying the supra- and infra-spinatus muscles) and the circumflex nerve (supplying the deltoid) each send a special branch to the shoulder-joint. The view that rheumatoid arthritis represents a dystrophy or defective nutrition of the joint dependent upon central nervous disorder is now very widely held, but there is much difference of opinion as to whether the nervous disorder is primary or whether it is set up by reflected irritation arising from the joint itself. There is nothing unreasonable in supposing that arthritis may arise in either way. In the entire absence of any indication of primary nervous disease it seems more likely that in the present case the dystrophy is due to reflected rather than to primary nervous disorder. It is also not improbable that persistent metallic contamination, occasioned by the nature of the patient's work, counts for something as a predisposing cause of his arthritic trouble.

Birmingham.

\section{Clinital a}

\section{MEDICAL, SURGICAL, OBSTETRICAL, AND THERAPEUTICAL.}

INVERSIO UTERI.

BY JOHN W. WALKER, M.R.C.S. ENG., L R.C.P. LOND., HONORARY SURGEON, CLAYTON HOSPITAL, WAKETIELD.

CASES of complete and spontaneous inversion of the uterus following closely upon labour are so rare that the notes of the following case may be useful. Galabin and Playfair state that the accident was only observed once in 190,800 deliveries at the Rotunda Hospital, Dublin.

On Sept. 14th, 1894, at 10 P.M. I was called to attend a woman and found labour just commencing. The os was dilated to about the size of a sixpence; the pains were frequent and strong. The labour proceeded steadily and at 2.15 A.M. the child was born. Immediately afterwards I placed $m y$ hand on the abdomen to secure contraction of the uterus and found it quite firm; my attention was then directed to the infant, and when I had tied the cord and was in the act of severing it the patient gave a loud scream as if in sudden and violent pain, and as I looked to see what was the cause I noticed the signs of great shock : the face was pallid, large beads of perspiration came out upon the forehead, the pulse was very small and rapid, and the skin cold and clammy. On examination I found that there had been a sudden and complete inversion of the uterus, the whole organ lying outside the vulva with the placenta attached, but little or no hæmorrhage taking place. I at once gave a hypodermic injection of ether, which quickly restored the patient, and I then removed the pillows to keep the head as low as possible. The placenta was easily peeled off the uterus, and I then commenced to reduce the inversion. When I had succeeded in getting the whole uterus well within the vagina and nearly everted, strong uterine contractions came on, which caused the fundus of the uterus to again become inverted; so strong were the contractions that my hand became completely cramped, and I was unable on this account to reduce it any further. I then sent for my assistant, Dr. E. C Maguire, who came and administered chloroform, the patient being by this time in a fairly satisfactory condition; but during the interval of time that had elapsed the inversion had again become much more marked, so that the internal surface of the fundus was presenting at the vulva. When she was completely anæsthetised I was soon able to reduce it with the exception of a small cupping of the fundus, but the uterine contractions were again so strong that my hand became cramped at this stage, and I was compelled to desist and ask Dr. Maguire to undertake the task while I attended to the anæsthetic. After a few minutes he was able to completely reduce the inversion, and then repeated injections of hot permanganate solution caused a satisfactory contraction of the uterus which remained. I am happy to say that there was no after trouble or any rise of temperature; but I kept her in the recumbent position for three weeks in orcler to secure permanent fixation of the uterus, and she made an uninterrupted recovery. I have recently attended her in a second confinement, which passed off without any special feature.

Wakefield.

\section{$\Lambda$ CASE OF CIRCUMSCRIBED TRAUMATIC ANEURYSM OF THE PALM.}

By ARnold CAddy, F.R.C.S. EnG.

TrIIS rare condition was present in a European female aged thirty-three years. On March 10th, 1896, while resting her right hand on a wineglass, the latter gave way and broke, cutting the palm of the hand. The wound, which bled profusely, was dressed at once and healed in five days. Four days later the wound was noticed to be tender when the patient was holding the reins in driving. Gradually at the site of the original wound a small, pulsating swelling appeared, which slowly increased in size. This swelling was only painful when the hand was used for grasping objects, but was not tender to pressure.

I saw the patient for the first time on April 17th, and then there was a rounded, pulsating swelling in the right palm the size of a nutmeg lying between the roots of the middle and ring fingers on a level with the head of the metacarpal bones. Pulsation ceased on compression of the radial and ulnar arteries at the right wrist, but returned at once when pressure was removed. On April 19th, the patient being under chloroform, assisted by Dr. H. C. Garth, of this city, I tied the right radial and ulnar arteries at the wrist. The wound was dressed antiseptically, the hand and forearm being put up on a straight splint. On April 21st the tumour had become quite hard and was without pulsation, the circulation in the fingers being perfect. On April 26th the wound was healed and the sutures were removed. The tumour had perceptibly shrunk. The splint was worn till May 8th and then the hand was only carried in a sling. By June 3rd the tumour had shrunk to the size of a small pea and the hand was in constant use.

I have recorded this case on account of the rarity of palmar aneurysms, whether spontaneous or traumatic. I was prepared here to tie the brachial artery if ligature of the radial and ulnar had failed, which event might bave occurred owing to the free anastomosis existing through the interosseous artery and the palmar arches. The patient herself was also desirous of trying the less severe measure first and the operation proved a complete success.

Calcutta.

DISLOCATION OF BOTH SHOULDER-JOINTSS. By G. E. HasLiP, M.D. BRUX., M.R.C.S. ENG., L.R.C.P. LOND.

I wAs called on June 1st to see a man, aged forty-one years, being told by his wife that he had had a fit the previous evening and had fallen, and he had been unable to use his arms since. The shoulders and arms were considerably swollen and bruised, and an examination showed a subcoracoid dislocation of both humeri, which were easily reduced by the extension method. Whether one or both were caused by the fit or the fall is, I think, purely a question of surmise. I may mention there was no previous history of any dislocation.

Northumberland-avenue, W.C.

The Sewerage of Aldershot Camp.-At a special meeting of the Aldershot district council on Saturday week the question of the disposal of the camp sewage was discussed. An appointment had been made with Colonel Parker and Dr. Kimshead on behalf of the Government to attend, but Mr. Robertson said that before these gentlemen came before the council it would be wise to consider the purport of their visit. 'The vice-chairman of the council said he should object to the spending of a single penny until there was a proper contract between them and the Government. They had paid £90 for valuing $\mathrm{cm}$ behalf of the Government, and they should be refunded that amount. 'Ihere were other outstanding accounts that ought to be attended to. The clerk said he was now attending to that matter, and the question was postponed entirely. 